\title{
浅析道路桥梁中的预应力施工及其应用
}

\author{
巴运良王孟玲 \\ 河南昌平建设开发有限公司 \\ DOI:10.32629/btr.v2i6.2247
}

[摘 要] 道路桥梁中的预应力施工应用, 是提升桥梁结构工程安全稳定及其承载力的重要手段, 因此为了充分发挥其预应力 施工技术的作用,本文阐述了道路桥梁中的预应力施工应用问题,对道路桥梁中的预应力施工要点及其应用进行了探讨分析。 [关键词] 道路桥梁; 预应力施工; 应用; 问题；要点

基于预应力施工技术的优势特点, 使其在现代道路桥工 程建设中得到广泛应用, 从而有效提高了道路桥梁工程质量 及其效益。但是由于各种因素的影响, 在道路桥梁中的预应 力施工应用过程中, 还存在诸多问题, 因此为了发挥预应力 施工技术的作用以及保障道路桥梁工程质量, 在其施工应用 过程中, 必须结合项目工程实际, 合理进行施工。以下就道路 桥梁中的预应力施工及其应用进行了探讨分析。

\section{1 道路桥梁中的预应力施工应用问题}

近年来, 道路桥梁中的预应力施工应用比较广泛, 并取 得明显成效, 但还是存在一些问题和, 比如道路桥梁施工过 程中的波纹管会受到外界因素影响, 导致管道堵塞。因此道 路桥梁工程建设过程中, 在混凝土浇筑施工时, 如果出现波 纹管堵塞, 就会影响后续作业的继续开展, 并且会浪费很多 人力与物力。波纹管堵塞原因主要有: 其一, 从业人员没有 依据预应力施工应用的相关要求进行作业, 导致波纹管出现 扭曲与变形现象; 其二, 混凝土振捣施工过程中, 混凝土材料 振捣不充分, 出现离析现象, 振捣力度过大或者时间过长, 施 工过程不规范, 并且振捣施工时没有及时避开波纹管, 造成 波纹管损坏或者移位。

\section{2 道路桥梁中的预应力施工要点分析}

2.1 严格钢材选择

预应力钢材的严格选择能够防止波纹管发生堵塞或者 出现裂缝。当前我国道路桥梁采用的预应力钢材主要包括预 应力矫直和冷拉钢丝、低松他和普通预应力钢绞线、预应力 钢筋等, 其中低松驰钢绞线应用比较广泛, 且轻便、高效。在 实际的道路桥梁施工中, 应仔细分析不同预应力钢材的特性, 全面考虑到各种因素, 如钢材表面的松驰度、钢材破断荷载 和尺寸、钢材延展率和伸长率、钢材几何参数和松散性、钢 材规格和品种等, 结合实际的道路桥梁施工要求, 选择合适 的预应力钢材, 保障施工质量和施工效益。

\section{2 合理选择预应力针具}

道路桥梁设计选择预应力混凝土结构形式, 在施工过程 中需要使用预应力针具, 因此选择合适的预应力针具, 并且 正确的使用针具, 对于整个道路桥梁一般工程施工建设实现 钢筋和混凝土的连接非常方便, 极大地提高了施工安全和施 工效率, 有效减少道路桥梁施工损失。针具自身具有良好的
优越性, 在道路桥梁施工中发挥着不可替代的重要作用。随 着道路桥梁预应力施工的应用越来越广泛, 预应力针具的各 方面性能也逐渐改善, 通过反复多次的试验和准确计算, 合 理设计针具尺寸, 从而提升预应力锚具性能。

\section{3 做好预应力体系设计}

道路桥梁预应力体系设计采用平坚相结合的钢束, 合理 构建空间曲线, 在顶部腹板位置集中针固, 齿板位置针固和 底板钢束尽量相互靠近, 这种布束结构具有以下特点: 其一, 这种预应力的力臂较大, 可充分发挥力学效应; 其二, 腹板和 布束之间的距离非常近, 在整个截面上传力路线均匀分布, 顶板束对腹板承托进行针固, 不需要设置一些复杂齿板, 实 现箱梁尺寸的受力控制设计; 其三, 平面上使用 $S$ 型线型, 对底板和顶板进行针固, 有效消除针固位置的横向作用力。

\section{4 预应力筋下料施工}

结合道路桥梁预应力施工设计要求进行张拉, 在针垫板 和钢管中进行灌浆操作, 形成完整的粘结段, 可有效提高预 应力筋的固定质量。工作人员在下料过程中, 应仔细清洁粘 结段和钢绞线, 细致、认真的清洁干净, 重点应注意结合段和 钢绞线上的油脂、PE 层等。同时, 在道路桥梁施工过程中, 应加强现场施工的沟通和监督, 从业人员必须严格按照预应 力筋下料施工要求进行操作, 将粘结段长度控制在标准尺寸 范围内, 确保其正确准确, 不偏不倚。

\section{5 穿索预应力筋}

道路桥梁中的预应力施工应用过程中, 通常预应力筋长 度比较长, 甚至超过 $160 \mathrm{~m}$, 在穿束施工过程中需穿过很多的 墩顶导向槽和转向装置, 整个箱梁中穿索 15 根钢绞线难度 非常大, 为了降低施工难度, 保障施工质量, 可逐一穿梭。

\section{6 张拉预应力筋要点}

道路桥梁应用预应力施工中的预应力筋张拉时, 应做好 预紧张拉和高应力张拉, 道路桥梁施工时应防止钢绞线被缠 绕, 确保顺利的进行后续施工, 保障预应力筋张拉质量。通过 预紧张拉可使钢绞线保持顺直, 并且为了保障预紧张拉质量, 应从预应力筋两头同时进行, 特别要注意拉伸力度, 不能过 小或者过大, 准确把握拉伸力度, 按照施工设计图要求, 放置 在正确的位置上, 避免其移动或者走位。同时, 完成预紧张拉 后, 应认真检查预紧张拉质量是否达标, 确保质量达标后再 
开始张拉预应力施工, 使用智能张拉机械设备, 有效保障施 工质量。

\section{7 压浆处理施工要点}

道路桥梁施工过程中, 应合理运用预应力施工, 做好压 浆处理施工。在实际应用中, 主要采用局部粘结的方式进行 压浆处理, 通过这种方式完成定衡量索针固处理, 确保压浆 处理后粘结力符合道路桥梁的施工规范标准, 粘结段的粘结 力达到 108\%以上, 压浆足够密实后, 才能确保针固质量合格。 预应力施工在道路桥梁施工中的应用, 应高度重视压浆处理, 实际操作施工完成后, 应做好相应的检查和实验, 确保压浆 处理的顺利进行。通常情况下, 道路桥梁施工中完成张拉环 节后的 20 小时内必须使用智能压浆机做好压浆处理, 压浆应 稳定、均匀, 保障压浆处理质量。

\section{3 道路桥梁中的预应力施工应用分析}

\section{1 做好相关准备工作}

准备工作对道路桥梁中的预应力施工应用非常重要, 主 要表现为: 一是预应力施工设计。预应力施工主要是对混凝 土和钢结构处理, 设计阶段要根据高速公路的实际情况和需 求对混凝土材料的荷载最大值进行明确的要求, 以免出现的 结构变形的问题, 而钢材料的选择则要保证负荷和承压性。 二是地基的处理。道路桥梁施工环境常会遇见诸如软地基等 形式的不良地质, 而与预应力施工虽然主要是针对桥梁结构, 但地基的处理效果会直接影响到施工质量。常见且有效的方 式主要有换填加固技术。

\section{$3.2 \mathrm{~T}$ 梁中的预应力施工应用}

一般道路桥梁施工会利用钢绞线来实现混凝土预应力 $\mathrm{T}$ 梁施工, 施工过程中, $\mathrm{T}$ 梁的跨径应该保持在 $20 \sim 50 \mathrm{~m}$ 。根据 静载试验结果, $\mathrm{T}$ 梁桥在设计承力荷载时, 桥梁使用性能能够 满足设计要求。同时采用 2 片梁双拼的方法进行 $\mathrm{T}$ 梁荷载试 验切实可行, 能够避免 $\mathrm{T}$ 梁在试验中发生侧倾失稳的情况。 但这种技术也存在一些不足之处, 例如, 为了得到较为可靠 的实验数据, 加载的重量和测试工作量成倍增加, 因此, 容易 发生严重偏载。

3.3 混凝土箱梁中的预应力施工应用分析

某大桥主桥设计为 $68 \mathrm{~m}+3 \times 110 \mathrm{~m}+68 \mathrm{~m}$ 预应力混凝土变 截面悬浇连续箱梁, 引桥设计为 $17 \mathrm{~m} \times 40 \mathrm{~m}$ 預制预应力混凝 土先简支后连续 $\mathrm{T}$ 梁, 大桥全长 $1161.80 \mathrm{~m}$ 。某大桥主要应用 的预应力连续箱梁技术完成修建的, 预应力混凝土连续箱梁
桥的跨径可达 $300 \mathrm{~m}$, 在这个跨径领域内, 它可与钢桥竞争。 箱形梁的优点是抗扭刚度大, 适用于曲线桥及承受较大偏心 荷载的直线桥。箱形梁主要有预应力混凝土箱形连续梁和钢 箱形梁。采用悬臂法施工的连续梁, 变高度梁又与施工的内 力状态相吻合。另外, 采用的变高度梁使梁体的外形和谐, 节省材料并增大桥下净空。在设计上, 箱形截面可极大地发 挥预应力的效用, 可提供很大的混凝土面积用于预应力束的 通过, 更关键的是可提供较大的截面高度, 使预应力束有较 大的力臂。

3.4 桥梁受弯构件中的预应力施工应用

预应力施工在道路桥梁工程项目施工过程中发挥着重 要作用, 主要表现为: 可以在很大程度上有效改变以及提升 工程材料混凝土的受拉性能以及受弯性, 众所周知, 由于混 凝土材料自身并不具备很强力的受拉和受弯性能, 这两种性 能在混凝土原料中体现相对较弱, 在道路桥梁工程项目的实 际施工过程中, 使用技术, 将其运用于受弯构件中去, 就可以 在很大程度上将混凝土材料的这种缺点加以改善, 最终也能 最大化地将其性能的优点进行发挥, 而且道路桥梁工程施工 作业过程中的抗弯性较差以及抗拉性较差的劣势也能得到 弥补。

\section{4 结束语}

综上所述, 近年来, 随着道路桥梁项目建设的日趋增多, 因此为了保证其工程质量, 必须提高相应的施工技术水平, 预应力施工技术是道路桥梁工程建设中常用的技术之一, 其 在道路桥梁工程中的合理运用, 能够有效提升桥梁结构工程 刚度, 并且可以有效保证整个桥梁工程质量, 并延长桥梁使 用寿命, 因此对道路桥梁中的预应力施工及其应用进行分析 具有重要意义。

[参考文献]

[1]谢荣,李明亮. 高速公路桥梁施工中预应力技术 [J]. 交 通世界,2016(03):18.

[2]罗远琴.高速公路桥梁施工中预应力施工技术的应用 [J].江西建材,2017(20):177+180.

[3]陈玥.试析公路桥梁施工中预应力技术的应用 [J].绿 色环保建材,2017(10):115。

[4]徐清风.高速公路桥梁施工中预应力施工技术的应用 [J].装饰装修天地,2018(05):47. 